\title{
Luto na infância: A perda através da literatura infantil
}

\author{
Grief in childhood: Loss through children's literature \\ Duelo en la infancia: Pérdida a través de la literatura infantil
}

Recebido: 07/06/2021 | Revisado: 13/06/2021 | Aceito: 24/06/2021 | Publicado: 10/07/2021

\author{
Rosa Carmem Rodrigues de Farias \\ ORCID: https://orcid.org/0000-0002-8541-299X \\ Faculdade de Ensino Superior do Piauí, Brasil \\ E-mail: rosacarminha@hotmail.com \\ Ruth Raquel Farias \\ ORCID: https://orcid.org/0000-0002-0988-0900 \\ Faculdade de Ensino Superior do Piauí, Brasil \\ E-mail: ruthraquelsf@gmail.com \\ Salma Suellen Ingelsrud Leal \\ ORCID: https://orcid.org/0000-0002-6086-6151 \\ Faculdade de Ensino Superior do Piauí, Brasil \\ E-mail: salmaleal@grupomagister.com.br \\ Érica Vanessa Rodrigues \\ ORCID: https://orcid.org/0000-0003-1283-374X \\ Faculdade de Ensino Superior do Piauí, Brasil \\ E-mail: ericavanessa@grupomagister.com.br
}

\begin{abstract}
Resumo
Discutir a temática morte é um desafio. Se para o adulto é algo demasiadamente misterioso, imagina falar sobre este tema para o público infantil, pois, devido seu nível de maturidade e desenvolvimento afetivo e emocional não está preparado para compreender tal menção. A presente pesquisa teve como objetivo compreender as diversas reações emocionais diante do luto na infância através da Literatura Infantil. Para tanto, foi realizada uma revisão literária narrativa com cunho qualitativo e análise minuciosa de publicações científicas que tratam o assunto. De uma forma geral, recomenda-se a utilização de um diálogo franco e claro, através de informações verdadeiras e honestas, promovendo-se a inserção e a construção do conceito de morte, como algo natural, desde o início da infância, com um comunicador aberto para esclarecimentos de dúvidas e uma escuta sensível, que favoreça a expressão dos diversos sentimentos que acometem uma criança nesta situação. Esta interação deve ser revestida de algumas estratégias e cuidados básicos, respeitando-se as capacidades cognitivas e emocionais da criança.
\end{abstract}

Palavras-chave: Literatura infantil; Morte; Luto; Crianças.

\begin{abstract}
Talking about the subject of death is challenging. If for adults it is something very mysterious, imagine talking about this subject for children, because, due to their level of maturity and affective and emotional development, they are not prepared to understand such a quote. This research aimed to understand the different emotional reactions to grief in childhood through children's literature. Therefore, a qualitative literary narrative review and a detailed analysis of scientific publications that address the subject were carried out. In general, frank and clear dialogue is recommended, through true and honest information, promoting the insertion and construction of the concept of death, as something natural, from early childhood, with a communicator open to clarifying doubts and sensitive listening, which favors the expression of the different feelings that affect a child in this situation. This interaction must be covered by some strategies and basic care, respecting the child's cognitive and emotional abilities.
\end{abstract}

Keywords: Children's literature; Death; Mourning; Kids.

\section{Resumen}

Hablar del tema de la muerte es un desafío. Si para los adultos es algo muy misterioso, imagínense hablando de este tema para niños, porque, por su nivel de madurez y desarrollo afectivo y emocional, no están preparados para entender tal cita. Esta investigación tuvo como objetivo comprender las diferentes reacciones emocionales al duelo en la infancia a través de la literatura infantil. Por ello, se realizó una revisión narrativa literaria cualitativa y un análisis detallado de las publicaciones científicas que abordan el tema. En general, se recomienda el diálogo franco y claro, a través de información veraz y honesta, promoviendo la inserción y construcción del concepto de muerte, como algo natural, desde la primera infancia, con un comunicador abierto a aclarar dudas y una escucha sensible, lo que favorece la expresión de los diferentes sentimientos que afectan a un niño en esta situación. Esta interacción debe estar cubierta por algunas estrategias y cuidados básicos, respetando las capacidades cognitivas y emocionales del niño.

Palabras-Clave: Literatura infantil; Muerte; Luto; Niños. 


\section{Introdução}

A morte é um evento inevitável na vida do ser vivente, logo, impacta na estrutura da personalidade do indivíduo em todas as fases que se apresenta. Segundo Torres (2012), na fase infantil a morte e o luto comprometem o desenvolvimento cognitivo e afetivo, sendo um dos princípios organizadores mais importantes do ciclo vital para estabelecer padrões do cotidiano de hábito e uma sucessão de sentimentos em etapas do luto como sadio ou patológico. Diante disso, é necessário perceber a intensidade de como estes sentimentos atingem a criança e como a mesma está preparada diante deste evento no contexto social. O autor também destaca elementos que contribuirão para desencadear este fato, como: idade, nível de desenvolvimento mental e cognitivo, constância psicológica e emocional e a relação com os laços afetivos.

No entanto, o autor sugere que algumas práticas sejam aplicadas para conduzir a criança neste processo com a intenção de que auxiliem a vivenciar o luto, tais como: acesso a literatura que aborde a temática, a família que apresente um diálogo que esclareça o assunto, a compreensão do tempo que a criança deve ter diante do evento para que possas absorver os sentimentos que são causados pela morte. Das práticas citadas, a motivação através do diálogo sobre a morte é uma das dificuldades existentes. Portanto, através da literatura infantil é possível favorecer a evitação dos medos e culpas fantasiosa que geram sofrimentos, portanto, aponta que para tratar sobre a morte com o público infantil é necessário respeitar o nível de desenvolvimento cognitivo e emocional, para isso, a posição do adulto deve ser flexível, prudente e protetora.

Segundo Lopes (2013), a grande questão é que as crianças não possuem vocabulários suficientes para expressar seus sentimentos, para tanto, deve ser inclusa uma linguagem intermediária para a compreensão, que seja favorável, mediante da comunicação do adulto. Como a criança compreende por outras perspectivas, dificulta seu entendimento no âmbito da definição de finitude. Logo, surge a pedagogia e a psicologia atrelada as descobertas da maturidade da criança, através dos estudos do desenvolvimento infantil.

Lopes (2013) afirma que a linguagem verbal-adulta e a não-verbal-infantil, contida no livro ilustrado ou em um livro bem escrito com palavras simples possibilitam a união das estratégias comunicativas ofertadas pela literatura infantil, onde na quebra dos paradigmas existentes na cultura da infância os conceitos de criança, morte e literatura serão atrelados para maior compreensão.

A leitura sempre leva a algum tipo de emoção ou sentimento, levando tanto ao consolo, animo, tristeza, alegria, aliviar a dor, a ansiedade, a solidão... Podendo auxiliar os sentimentos e algumas situações vividas na vida (Smith, 2003).

Assim sendo, a criança através deste contato com a literatura infantil pode ter uma compreensão mais flexível da temática sobre a morte, partindo da observação através das diversas estratégias de linguagem apresentadas pelos pais, parentes ou mesmo professores.

Diante do exposto, compreender as diversas reações emocionais diante do luto na infância através da Literatura Infantil, é um dos objetivos desta pesquisa, haja vista, que o público em estudo não apresenta maturidade emocional para tais reações, diante da perda e do luto. Portanto, o incentivo do diálogo sobre a morte com a criança através dos vários gêneros textuais foi outra proposta voltada para esta pesquisa, para tanto, a necessidade de conhecer diferentes padrões de comportamentos e etapas diferenciadas do desenvolvimento para buscar esta compreensão.

\section{Metodologia}

Para o atualda trabalho realizou-se uma revisão literária narrativa, que permitem descrever e refletir a respeito de determinado assunto, sob o ponto de vista teórico ou contextual. De cunho qualitativo, haja vista, que a pesquisa é compreendida como suporte para atender as necessidades intencionais e seu significado inerente às relações e estruturas envolvidas (Minayo, 2004.) 
De acordo com os princípios da pesquisa, foram levantados dados de publicações científicas que incluíram os descritores: morte, luto, perda, crianças, literatura infantil, em bases de dados eletrônicos como Scielo, Bvs-Psi e Lilacs. e 5 (cinco) livros-imagens, a destacar: Mamãe é uma estrela; O garoto da cadeira de rodas voadora; do fim ao começo: falando sobre a perda.; mas por quê???; Que saudades de você...

Foram analisados trabalhos que apresentaram os seguintes critérios de inclusão: publicações de 2000 a 2021 ; artigos que indicavam a ação da Literatura Infantil no contexto de morte e perda.

\section{Resultados e Discussão}

\section{A morte sob os diferentes pontos de vistas na evolução dos tempos}

A morte diante das civilizações tem um papel de grande relevância nas sociedades. Segundo Giacoia (2005), acordo com a cultura de cada sociedade o olhar para a morte tem papel diferenciado na constituição da identidade coletiva, sendo apresentada a seguir diversas formas de ver a constituição da morte em sociedades diferentes.

Loterman (2010) afirma que os mesopotâmicos sepultavam seus mortos acompanhando vários de seus pertences que marcavam sua história pessoal e familiar. Esta maneira de ver a morte para os povos da Mesopotâmia era uma passagem do mundo da vivência para o mundo da morte.

O autor, ainda apresenta, que na Grécia, para marcar uma nova existência, vida x morte, era costume cremar os corpos dos mortos, cujas cinzas eram recolhidas à família para manter viva a memória dos mortos.

Os hindus, praticavam a cremação, onde suas cinzas eram lançadas a natureza para representar a passagem a outro plano da existência humana.

Para os judeus a morte era vista como passagem para outra dimensão, no qual o ser despertará para a ressurreição. Ou seja, uma vida nova.

Para a civilização cristã a morte é analógica a um sono profundo, no qual deve despertar na ressurreição, período intermediário, pois a morte é vista como uma passagem.

\section{A morte e o luto na trajetória da literatura infantil}

A morte por ser um evento inerente à natureza humana trouxe à literatura infantil uma gama de manifestações orais que gerou questionamentos sobre a temática em diversas áreas de estudo.

Loterman (2010) apresenta as mais variadas cenas de mortes apresentadas em contos narrativos populares. Um dos países em destaque pela quantidade de contos coletados por Charles Perrault, foi França, no século XVII.

Com o passar dos tempos, inúmeras transformações ocorreram favorecendo ao sujeito um olhar diferenciado sobre a morte e o luto, para tanto passa por vários estágios, resultando uma interação de aceitação consigo e com o outro. Loterman, (2010, p. 47) afirma que em nossa sociedade, as crianças são afastadas de situações que as façam deparar com a morte. Logo, a literatura promove uma aproximação necessária através das histórias que abordem a temática em estudo. Apesar de ser tratada como um tabu, há obras que se preocupam em tratar do tema sem o aspecto sombrio e amedrontador que ele teve durante tanto tempo.

Diversos autores têm-se preocupado a relatar o tema a crianças de forma para que ocorra a compreensão. Levando a criança a uma realidade diferente e tentando leva-la de forma mais leve ao tema (Gomes; Medeiros, 2014).

Desta forma, a literatura infantil permite ao público infantil estratégias para compreender o mundo que o rodeiam e de tudo o que faz parte dela. Assim, as vidas dos personagens são projetadas de maneira simbólica, metafórica e objetiva para adequar a compreensão da realidade infantil. 


\section{Biblioterapia: a leitura como terapia}

Diante do contexto da perda e do luto, afloram vários sentimentos que podem apresentar uma constância de tempo duradoura e, se forem bem administrados a permanência destes sentimentos passam sem causar nenhum prejuízo nas emoções.

Pode-se destacar a função da Biblioterapia, que é uma ferramenta utilizada como tratamento alternativo, mais que serve de alívio para as angústias, medos conflitos, angústias e dores dos leitores que utilizarem esta prática, pois através da linguagem verbal e não-verbal contribuem para as pessoas com transtornos emocionais.

Pereira (2016), afirma que, apesar de ser pouco utilizada, a biblioterapia tem muita eficácia. Desde 1802 médicos norte-americanos acreditavam que livros selecionados com textos adequados para as necessidades dos indíviduos surtiam efeitos positivos em seus resultados e adequação no equilíbrio emocional do sujeito.

Ribeiro (2006) informa que no ano de 1949 a biblioterapia foi debatida cientificamente como recurso terapêutico e após as comprovações de Shrodes, foi consolidada como guia na solução de problemas pessoais através da leitura dirigida e coadjuvante terapêutica. O Projeto de Lei $n^{\circ}$. 4.186, de 11 de julho de 2012, foi apresentado na Câmara dos Deputados que trata do uso da Biblioterapia em hospitais públicos brasileiros.

[...] a prática da biblioterapia é um dos recursos terapêuticos que através da ressignificação da leitura prazerosa de qualquer texto escolhido selecionado ou mesmo indicado que após a leitura, narrativa ou contada venham resultar numa paz de espírito tamanha amenizando as tensões psicossomáticas do sujeito cognitivo, consequentemente proporcionando leveza mental.

A leitura também leva a leveza e a paz do espírito, mesmo sendo narrada ou contada. Portanto, a terapia através da leitura faz com que o sujeito distancie-se de suas angústias e sofrimentos adquirindo uma autonomia em relação as suas emoções (Bahiana, 2009).

Pereira (2016), classifica a biblioterapia em três etapas, sendo: institucional (refere-se as estratégias que auxiliam na aprendizagem do leitor, sendo informativa e recreativa), Clínica (refere-se a uma prática imaginativa, com grupo de pacientes que passam por problemas emocionais ou comportamentais) e Desenvolvimental(sua proposta é auxiliar sujeitos a desenvolverem atividades semelhantes e suportarem problemas diários).

Valência (2005), afirma que a leitura desperta no sujeito o autoconhecimento, auxiliando a descobrir qualidades e habilidades de superação emocional, onde o sujeito passa compreender a si, verificando suas características no decorrer da sua história.

Caldin (2001), explica que a leitura orientada é um processo de socialização, pois muito dos leitores sentem-se isolados, e através da leitura interagem com um mundo sem julgamento e fazem criações de sua mente sem degradar seus sentimentos.

A leitura permite a diferença de emoções, ocorrendo alivio, piedade e leva a uma leveza interior. A leitura possui o poder de alivio e cura interior(Caldin, 2001,p. 32)

Caldin (2001) ainda apresenta algumas contribuições benéficas e importantes da Biblioterapia como a troca de experiências em atividades em grupo, pois a busca das soluções para os problemas surge como mecanismo de ajuda. A relação empática do leitor associada aos personagens auxilia o leitor a compreender suas limitações, dores, reações, conflitos, angústias e medos.

\section{Obras literárias no âmbito escolar}

Quando se trata de leitura permeando uma escola, pensa-se em livros no contexto da Literatura Infantil como processo facilitador que aprimora a compreensão dos leitores em suas práticas culturais e educativas. Para tanto, os acervos que 
compõem a literatura infantil são formados por textos em prosa (contos, crônicas, novelas, memórias, biografias e teatro); textos em versos (poemas, cantigas, parlendas, adivinhas); livros de imagens e livros de histórias em quadrinhos. Apesar de uma variedade de gêneros textuais e abordagem em diversos temas, é possível perceber uma escassez na temática sobre a morte, apesar de muitos livros abordarem temas sobre conflitos que geram tristezas, decepções, fracassos, dentre outros.

Kovács (2005), afirma, que a escassez de livros sobre a morte pode remeter-se ao fato da falta de preparo dos cuidadores (familiar/professor), por preconceito ou conteúdo metodológico para lidar com temas que envolvam emoções e sentimento em relação a finitude da vida.

Pela leitura da obra literária, o conceito da morte pode ter significados construídos e através dessas construções, as expressões darem novas compreensões que auxiliem o evento.

A literatura, como objeto da linguagem, estruturado por palavras e discursos, é fator indispensável de humanização, pois consente que os sentimentos passem de simples emoção para uma forma mais concreta, visto que são experienciados pelo leitor. Com isso quer-se dizer que a leitura de uma situação dramática, por exemplo, possibilita ao leitor experimentar emoções inerentes ao conflito nela estabelecido. (Ramos, 2010. p.86)

O professor, nas instituições escolares, exerce a função mediadora no processo do ensino-aprendizagem, proporcionando uma aproximação entre o leitor e o texto. E a escola é o elo entre a criança e o material literário.

A leitura continuamente envolve algum tipo de emoção, sendo capaz de estimular e aliviar a curiosidade, prestar consolo, encorajar, fazer surgir paixões, aliviar a solidão, o tédio e a ansiedade, servir de paliativo à tristeza e, ocasionalmente, como anestesia. (Smith, 2003. p. 212).

O caráter subjetivo da obra literária contribui na desmistificação do conceito de morte para reduzir a dor da criança que passa uma perda significativa, conforme a interpretação do texto, utilizando expressões eufemística no processo de construção de conhecimento, tais como: virou estrela, foi para o céu, foi viajar, dentre outras.

Desta maneira, alguns livros, principalmente os de literatura infantil e infanto-juvenil, podem ajudar as crianças a lidarem com as mais diversas situações de vida, tendo em consideração a empatia com que seus autores abordam temas como o abandono, o distanciamento, a perda e a morte.

\section{Conclusão}

De acordo com o estudo realizado percebeu-se que os resultados explicitam que a morte e o luto são temáticas necessárias em discussão com o público infantil, haja vista que as reações emocionais advindas desta temática afetam o emocional quando não preparado. Sendo assim familiares, professores e cuidadores devem favorecer através do diálogo simples e aberto uma linguagem que oportunize a compreensão e aceitação da criança diante do exposto. Desta forma, a literatura infantil tem contribuído, embora com uma escassez de gêneros textuais sobre a temática, para a compreensão das crianças no que compete a morte e o luto.

Através de mecanismos como metáforas e simbolismos, a temática pode insinuar uma leveza e compreensão na explicitação quando apresentada a criança como algo que não deve ser temido, mas discutido e compreendido, uma vez que faz parte do desenvolvimento vital.

Sabendo da relevância deste diálogo com a criança, a pesquisa passa por diversos estilos de escrita comuns aos gêneros textuais, como os contos de fada, os clássicos e os livros-ilustrados, buscando as respostas que são oferecidas às crianças quando um personagem morre em uma história e a relação que fazem diante da perda e do luto. A literatura infantil é a base relacional da criança e a morte, desde o gênero textual contos de fada até os livros-imagens. 
No presente trabalho, trouxemos análises de narrativas destinadas ao público infantil que trazem representações distintas acerca do mesmo tema. De modo geral, essa pesquisa comprova que é possível compreender a morte e o luto sob as mais diversas representações.

Para tanto, a biblioterapia, favorece um alinhamento nas emoções pois comunica através da linguagem verbal e nãoverbal com o leitor, favorecendo que seus desenvolvimentos emocionais sejam associados a leitura.

\section{Referências}

Aberastury, A. (1984). A percepção da morte na criança e outros escritos. Porto Alegre: Artmed.

Barbosa, A. (2010). Processo de Luto. In A. Barbosa \& I. Neto (Eds.), Manual de Cuidados Paliativos (2ª ed; pp. 111-125). Lisboa: Faculdade de Medicina de Lisboa.

Boss, P., (2008). A perda ambígua -Morte na família: Sobrevivendo às perdas. Porto Alegre, RS: Artmed. Bouteiller, B. le, (2017). Luto e melancolia variações com o texto de Freud (B. Maranhão, Trad.). Reverso, 39(73). http://pepsic.bvsalud.org/scielo.php?script=sci_arttext\&pid=S010273952017000100004

Bowlby, J., (1990). Formação e rompimento dos laços afetivos (4ª ed.; A. Cabral,Trad). São Paulo: Martins Fontes.

Bowlby, J., (1998). Apego e perda (2ª ed.; A. Cabral, Trad.). São Paulo: Martins Fontes. (Trabalho original publicado em 1973)

Bromberg, M. H. P. F., (2000). A psicoterapia em situação de perdas e luto. Campinas: Livro Pleno Bomtempo, E,. (2001). A brincadeira de faz-de-conta: lugar do simbolismo, da representação, do imaginário. In: T. M. Kishimoto (Org.), Jogo, brinquedo, brincadeira e a educação (2a ed.; pp. 57 -71). São Paulo: Cortez.

Castilhos, G. \& Bastos, A., (2013). A função constitutiva do luto na estruturação do desejo.Estilos Clínica, 18(1), 89-106. http://pepsic.bvsalud.org/pdf/estic/v18n1/a06v18n1.pdf.

Cavalcanti, A., Samczuck, M. \& Bonfim, T. (2013). O conceito psicanalítico do luto: uma perspectiva a partir de Freud e Klein. http://www.metodista.br/revistas/revistasims/index.php/PINFOR/articule/viewFILE/4552/3751.

Chiara, I. G. D. et al. (2008). Normas de documentação aplicadas à área de Saúde. Rio de Janeiro: E-papers.

Cole, M., \& Cole, S. R. (2009). Experiências iniciais e vida futura: O desenvolvimento da criança e do adolescente (4ª. ed.; pp. 274-304). Porto Alegre: Artmed. Flick, U., (2009). Desenho da pesquisa qualitativa. Porto Alegre: Artmed.

Correia, A. (2013). O garoto da cadeira de rodas voadoras. - Sã Paulo: Paulinas - (Coleção fazendo a diferença) Série Pula-ronda.

Franco, M. H. P., \& Mazorra, L. (2007). Criança e luto: Vivências fantasmáticas diante da morte do genitor. Estudos de Psicologia, 24(4), 503-511. http://www.scielo.br/pdf/estpsi/v24n4/v24n4a09.pdf.

Giacoia, J. O. (2005). A visão da morte ao longo do tempo. Disponível em: GIACOIA, J. O. A visão da morte ao longo do tempo.

Guarnieri, M. C. M. (2010). Do fim ao começo: falando sobre perdas, luto e morte.2. ed. São Paulo; Paulinas - (Coleção Adolescer).

Lopes. (2013). Produção oral narrativa e compreensão a partir de uma perspectiva de desenvolvimento comunicativo. Porto Alegre: Artmed.

Lottermann, C. (2010). Representações da morte na literatura infantil e juvenil brasileira. Anais do SILEL. Volume 1. Uberlândia: EDUFU.

Minayo, M. C. S. (2004). O desafio do conhecimento: pesquisa qualitativa em saúde. 8. ed. São Paulo (SP): Hucitec; p.9-18.

Paiva, Lucélia Elizabeth. (2011). A arte de falar da morte para crianças: a literatura infantil como recurso para abordar a morte com crianças e educadores. Aparecida-SP: Ideias \& Letras.

Palmer, P. (2011). Que saudades de você: para aprender a lidar com o luto e as perdas. São Paulo: Paulinas.

Ramos, F. B. (2010). Por que a literatura? Ciberteologia- Revista de Teologia \& Cultura [online], Ano VI, 30, 85-95. São Paulo. R http://ciberteologia.paulinas.org.br/ciberteologia/index.php/literatura/por-que-a-literatura/.

Smith, F. (2003). Compreendendo a leitura: uma análise psicolinguística da leitura e do aprender a ler. Porto Alegre: Artmed.

Torres, W. C. (2012). A Criança Diante da Morte: Desafios. São Paulo. Casa do Psicólogo. 